INTERNATIONAL GEOLOGY REVIEW, 2015

http://dx.doi.org/10.1080/00206814.2015.1114908

Online supplementary material for

\title{
Outburst floods of the Maly Yenisei. Part I - Review
}

\author{
Jigjidsurengiin Batbaatar and Alan R. Gillespie
}

Quaternary Research Center, University of Washington, Seattle, WA, USA

Corresponding author: J. Batbaatar (bataa@uw.edu)

\section{Sensitivity of ${ }^{10} \mathrm{Be}$ age calculations to the scaling schemes}

The published ${ }^{10} \mathrm{Be}$ ages were recalculated using CRONUS-Earth version 2.2 (Balco et al. 2008) with the globally calibrated ${ }^{10} \mathrm{Be}$ production rate of $3.99 \pm 0.22$ atoms $\mathrm{g}^{-1} \mathrm{yr}^{-1}$ (Heyman 2014) when referenced to the scaling of Stone (2000). Gillespie et al. (2008) used CRONUS-Earth version 1.2 with a production rate of 5.2 atoms $\mathrm{g}^{-1} \mathrm{yr}^{-1}$ and adopted the scaling of Lal (1991) and corrected for paleomagnetic variation, which is called Lm in Table S1. Arzhannikov et al. (2012) reported using the production rate of $4.49 \pm 0.29$ atoms $\mathrm{g}^{-1} \mathrm{yr}^{-1}$; Rother et al. (2014) used $4.43 \pm 0.52$ atoms $\mathrm{g}^{-1} \mathrm{yr}^{-1}$ referenced to Dunai scaling (Dunai 2001). For consistency we accepted only the ages with the scaling of Stone (2000) without paleomagnetic correction, because the total $1 \sigma$ uncertainty of the ages from the other scaling schemes did not exceed the margin of analytical error. In the recalculation we used $2.7 \mathrm{~g} \mathrm{~cm}^{-3}$ for sample density (same value used in Gillespie et al. 2008), instead of $2.5 \mathrm{~g} \mathrm{~cm}^{-3}$ in Arzhannikov et al. (2012) and 2.6 $\mathrm{g} \mathrm{cm}^{-3}$ in Rother et al. (2014). Using $2.6 \mathrm{~g} \mathrm{~cm}^{-3}$ would make less than $0.3 \%$ difference in the apparent age for samples $<10 \mathrm{~cm}$ thick. No burial history and zero erosion were assumed in the recalculation of the ${ }^{10} \mathrm{Be}$ ages. 
Table S1. ${ }^{10} \mathrm{Be}$ exposure ages (in $\mathrm{ka} \pm 1 \sigma$ ) for all the samples summarized in Figure 10 in the main text calculated using various scaling schemes for spallation. St: Lal (1991)/Stone (2000); De: Desilets et al. (2003, 2006); Du: Dunai (2001); Li: Lifton et al. (2005); Lm: Time-dependent Lal (1991)/Stone (2000). The ages shown in bold (St) are discussed in the text.

\begin{tabular}{|c|c|c|c|c|c|}
\hline Sample ID & St & De & $\mathrm{Du}$ & $\mathrm{Li}$ & $\mathrm{Lm}$ \\
\hline \multicolumn{6}{|c|}{ Darhad basin group (from Gillespie et al. 2008) } \\
\hline 081400-arg-Tin-01 & $21.3 \pm 1.3$ & $21.6 \pm 1.7$ & $21.8 \pm 1.6$ & $21.1 \pm 1.5$ & $21.5 \pm 1.2$ \\
\hline 081400-arg-Tin-01b & $23.9 \pm 1.5$ & $24.2 \pm 1.9$ & $24.4 \pm 1.8$ & $23.7 \pm 1.6$ & $24.1 \pm 1.4$ \\
\hline 081700-rmb-Tin-01a & $34.6 \pm 2.2$ & $34.8 \pm 2.7$ & $34.9 \pm 2.6$ & $33.7 \pm 2.4$ & $34.7 \pm 2.0$ \\
\hline 081700-rmb-Tin-01c & $28.0 \pm 1.7$ & $28.3 \pm 2.2$ & $28.4 \pm 2.1$ & $27.5 \pm 1.9$ & $28.2 \pm 1.6$ \\
\hline 081700-arg-Uzg-002d & $16.8 \pm 1.1$ & $16.9 \pm 1.4$ & $17.1 \pm 1.3$ & $16.6 \pm 1.2$ & $17.0 \pm 1.0$ \\
\hline 081700-arg-Uzg-003 & $30.5 \pm 2.0$ & $30.5 \pm 2.4$ & $30.6 \pm 2.3$ & $29.5 \pm 2.1$ & $30.6 \pm 1.8$ \\
\hline 080900-arg-Gar-Ia-001 & $23.7 \pm 1.5$ & $24.1 \pm 1.8$ & $24.3 \pm 1.8$ & $23.5 \pm 1.6$ & $23.9 \pm 1.4$ \\
\hline 080900-arg-Gar-Ia-002 & $21.1 \pm 1.3$ & $21.5 \pm 1.6$ & $21.6 \pm 1.6$ & $21.0 \pm 1.5$ & $21.3 \pm 1.2$ \\
\hline 081000-arg-Gar-Ia-003 & $25.1 \pm 1.5$ & $25.5 \pm 1.9$ & $25.6 \pm 1.9$ & $24.8 \pm 1.7$ & $25.3 \pm 1.4$ \\
\hline 081000-arg-Gar-Ia-010 & $45.4 \pm 2.7$ & $45.9 \pm 3.4$ & $45.9 \pm 3.4$ & $44.4 \pm 3.0$ & $45.4 \pm 2.5$ \\
\hline 081000-arg-Gar-Ia-011 & $44.7 \pm 4.1$ & $45.1 \pm 4.5$ & $45.2 \pm 4.4$ & $43.7 \pm 4.1$ & $44.7 \pm 3.8$ \\
\hline 081000-arg-Gar-Ia-012 & $19.5 \pm 1.2$ & $19.8 \pm 1.5$ & $20.0 \pm 1.5$ & $19.4 \pm 1.3$ & $19.7 \pm 1.1$ \\
\hline 081000-arg-Gar-Ia-013 & $20.3 \pm 1.3$ & $20.7 \pm 1.6$ & $20.8 \pm 1.6$ & $20.2 \pm 1.4$ & $20.5 \pm 1.2$ \\
\hline 081000-arg-Gar-IIa-005 & $30.4 \pm 1.9$ & $30.8 \pm 2.4$ & $30.9 \pm 2.3$ & $29.9 \pm 2.1$ & $30.6 \pm 1.7$ \\
\hline 081000-arg-Gar-IIa-007 & $18.6 \pm 1.1$ & $18.9 \pm 1.4$ & $19.0 \pm 1.4$ & $18.5 \pm 1.3$ & $18.8 \pm 1.1$ \\
\hline 081000-arg-Gar-IIa-008 & $21.4 \pm 1.3$ & $21.7 \pm 1.6$ & $21.9 \pm 1.6$ & $21.2 \pm 1.4$ & $21.6 \pm 1.2$ \\
\hline 082100-arg-Huj-01a & $246.9 \pm 19.2$ & $247.2 \pm 22.2$ & $247.4 \pm 21.6$ & $237.5 \pm 19.7$ & $246.4 \pm 17.5$ \\
\hline 082100-arg-Huj-01b & $111.9 \pm 6.7$ & $112.2 \pm 8.6$ & $112.3 \pm 8.3$ & $108.1 \pm 7.5$ & $111.7 \pm 6.2$ \\
\hline 082100-arg-Huj-01c & $142.8 \pm 8.6$ & $143.1 \pm 11.0$ & $143.1 \pm 10.6$ & $137.6 \pm 9.6$ & $142.4 \pm 7.9$ \\
\hline 082100-arg-Huj-02c & $16.5 \pm 1.1$ & $16.8 \pm 1.3$ & $16.9 \pm 1.3$ & $16.5 \pm 1.2$ & $16.6 \pm 1.0$ \\
\hline 082100-arg-Huj-02d & $45.3 \pm 2.8$ & $45.6 \pm 3.5$ & $45.7 \pm 3.4$ & $44.2 \pm 3.1$ & $45.3 \pm 2.6$ \\
\hline 082100-arg-Huj-02e & $29.1 \pm 1.9$ & $29.4 \pm 2.3$ & $29.6 \pm 2.3$ & $28.6 \pm 2.1$ & $29.2 \pm 1.8$ \\
\hline \multicolumn{6}{|c|}{ East Sayan mountains group (from Arzhannikov et al. 2012) } \\
\hline S07BE6 & $18.2 \pm 3.2$ & $18.6 \pm 3.4$ & $18.7 \pm 3.4$ & $18.2 \pm 3.3$ & $18.3 \pm 3.2$ \\
\hline S07BE7 & $20.6 \pm 1.4$ & $21.1 \pm 1.7$ & $21.2 \pm 1.7$ & $20.6 \pm 1.5$ & $20.8 \pm 1.3$ \\
\hline S07BE8 & $18.1 \pm 1.5$ & $18.5 \pm 1.8$ & $18.6 \pm 1.7$ & $18.1 \pm 1.6$ & $18.2 \pm 1.5$ \\
\hline S07BE9 & $17.4 \pm 1.3$ & $17.8 \pm 1.6$ & $17.9 \pm 1.6$ & $17.4 \pm 1.5$ & $17.5 \pm 1.3$ \\
\hline S07BE10 & $26.4 \pm 1.9$ & $27.1 \pm 2.4$ & $27.2 \pm 2.3$ & $26.4 \pm 2.1$ & $26.6 \pm 1.9$ \\
\hline S07BE11 & $24.3 \pm 1.8$ & $24.9 \pm 2.2$ & $25.1 \pm 2.1$ & $24.3 \pm 2.0$ & $24.5 \pm 1.7$ \\
\hline S07BE12 & $25.1 \pm 2.9$ & $25.7 \pm 3.2$ & $25.9 \pm 3.1$ & $25.1 \pm 3.0$ & $25.3 \pm 2.8$ \\
\hline S07BE13 & $27.1 \pm 1.9$ & $27.7 \pm 2.4$ & $27.8 \pm 2.3$ & $26.9 \pm 2.1$ & $27.2 \pm 1.8$ \\
\hline S07BE14 & $26.0 \pm 2.5$ & $26.6 \pm 2.9$ & $26.7 \pm 2.8$ & $25.9 \pm 2.7$ & $26.2 \pm 2.5$ \\
\hline S07BE15 & $44.5 \pm 3.6$ & $45.4 \pm 4.3$ & $45.4 \pm 4.2$ & $43.9 \pm 3.9$ & $44.6 \pm 3.5$ \\
\hline S07BE16 & $70.4 \pm 5.7$ & $71.8 \pm 6.7$ & $71.8 \pm 6.6$ & $69.4 \pm 6.1$ & $70.5 \pm 5.5$ \\
\hline S07BE17 & $17.0 \pm 1.4$ & $17.5 \pm 1.6$ & $17.6 \pm 1.6$ & $17.1 \pm 1.5$ & $17.2 \pm 1.3$ \\
\hline S07BE18 & $18.1 \pm 1.6$ & $18.5 \pm 1.9$ & $18.7 \pm 1.8$ & $18.1 \pm 1.7$ & $18.2 \pm 1.6$ \\
\hline
\end{tabular}


Table S1 (continued).

\begin{tabular}{|c|c|c|c|c|c|}
\hline Sample ID & St & De & $\mathrm{Du}$ & $\mathrm{Li}$ & $\mathrm{Lm}$ \\
\hline \multicolumn{6}{|c|}{ Otgontenger mountain group (from Rother et al. 2014) } \\
\hline MON-D-II-I & $16.6 \pm 1.0$ & $16.6 \pm 1.3$ & $16.7 \pm 1.2$ & $16.5 \pm 1.2$ & $16.6 \pm 1.0$ \\
\hline MON-D-II-II & $16.5 \pm 1.0$ & $16.4 \pm 1.3$ & $16.6 \pm 1.2$ & $16.3 \pm 1.1$ & $16.5 \pm 0.9$ \\
\hline MON-D-II-III & $33.5 \pm 2.0$ & $32.6 \pm 2.5$ & $32.8 \pm 2.4$ & $32.0 \pm 2.2$ & $32.9 \pm 1.9$ \\
\hline MON-D-IV-I & $21.6 \pm 1.3$ & $21.3 \pm 1.6$ & $21.4 \pm 1.6$ & $21.0 \pm 1.5$ & $21.5 \pm 1.2$ \\
\hline MON-D-IV-II & $18.7 \pm 1.2$ & $18.5 \pm 1.4$ & $18.7 \pm 1.4$ & $18.3 \pm 1.3$ & $18.6 \pm 1.1$ \\
\hline MON-D-IV-III & $15.0 \pm 0.9$ & $14.9 \pm 1.2$ & $15.1 \pm 1.2$ & $14.9 \pm 1.1$ & $15.0 \pm 0.9$ \\
\hline MON-F-I-I & $26.8 \pm 1.7$ & $26.0 \pm 2.0$ & $26.2 \pm 2.0$ & $25.6 \pm 1.8$ & $26.4 \pm 1.5$ \\
\hline MON-F-I-II & $28.5 \pm 1.8$ & $27.6 \pm 2.1$ & $27.7 \pm 2.1$ & $27.1 \pm 1.9$ & $28.1 \pm 1.6$ \\
\hline MON-F-I-IV & $23.4 \pm 1.4$ & $22.8 \pm 1.8$ & $22.9 \pm 1.7$ & $22.5 \pm 1.6$ & $23.2 \pm 1.3$ \\
\hline MON-E-III-I & $19.2 \pm 1.2$ & $18.8 \pm 1.5$ & $19.0 \pm 1.4$ & $18.6 \pm 1.3$ & $19.1 \pm 1.1$ \\
\hline MON-E-III-II & $18.9 \pm 1.2$ & $18.5 \pm 1.5$ & $18.7 \pm 1.4$ & $18.4 \pm 1.3$ & $18.8 \pm 1.1$ \\
\hline MON-E-III-III & $18.6 \pm 1.1$ & $18.2 \pm 1.4$ & $18.4 \pm 1.4$ & $18.1 \pm 1.3$ & $18.5 \pm 1.1$ \\
\hline MON-D-I-I & $45.1 \pm 2.8$ & $43.4 \pm 3.3$ & $43.6 \pm 3.2$ & $42.3 \pm 3.0$ & $44.0 \pm 2.5$ \\
\hline MON-D-I-II & $22.4 \pm 1.4$ & $22.0 \pm 1.7$ & $22.2 \pm 1.6$ & $21.8 \pm 1.5$ & $22.2 \pm 1.3$ \\
\hline MON-D-I-III & $41.9 \pm 2.6$ & $40.4 \pm 3.1$ & $40.6 \pm 3.0$ & $39.5 \pm 2.8$ & $41.0 \pm 2.3$ \\
\hline MON-E-I-I & $42.9 \pm 2.6$ & $40.3 \pm 3.1$ & $40.5 \pm 3.0$ & $39.2 \pm 2.8$ & $41.9 \pm 2.4$ \\
\hline MON-E-I-II & $59.5 \pm 3.6$ & $55.8 \pm 4.3$ & $55.9 \pm 4.2$ & $54.1 \pm 3.8$ & $58.1 \pm 3.3$ \\
\hline MON-E-I-III & $31.9 \pm 2.4$ & $30.3 \pm 2.7$ & $30.4 \pm 2.6$ & $29.6 \pm 2.5$ & $31.4 \pm 2.3$ \\
\hline MON-E-II-I & $63.5 \pm 4.0$ & $59.6 \pm 4.7$ & $59.7 \pm 4.5$ & $57.9 \pm 4.2$ & $62.1 \pm 3.7$ \\
\hline MON-E-II-II & $23.6 \pm 1.5$ & $22.6 \pm 1.7$ & $22.7 \pm 1.7$ & $22.2 \pm 1.6$ & $23.4 \pm 1.4$ \\
\hline MON-E-II-III & $40.1 \pm 2.5$ & $37.6 \pm 2.9$ & $37.8 \pm 2.8$ & $36.7 \pm 2.6$ & $39.2 \pm 2.2$ \\
\hline
\end{tabular}




\section{Calculation of bed shear stress and the size of mobilized particles}

Komatsu et al. (2009) estimated that the peak discharge rate of an instant flood from a $172 \mathrm{~m}$ deep Darhad lake would reach $\sim 3.5 \times 10^{6} \mathrm{~m}^{3} \mathrm{~s}^{-1}$ and rapidly decrease to $\sim 0.5 \times$ $10^{6} \mathrm{~m}^{3} \mathrm{~s}^{-1}$ after $\sim 20$ hours. We used the range of peak discharges of Komatsu et al. (2009) and calculated the bed shear stress on the Maly Yenisei gorge immediately upstream the Tengis glacier. Then, using the bed shear stress we calculated the maximum size of particles (with average rock density of $2700 \mathrm{~kg} \mathrm{~m}^{-3}$ ) that could be mobilized in the flood. The approach is detailed below:

Table S2. Parameters used for the calculation of bed shear stress and size of particles mobilized.

\begin{tabular}{ll}
\hline Parameter, symbol & Values used [unit] \\
\hline Peak discharge, $\mathrm{Q}$ & $0.5-3.5\left[10^{6} \mathrm{~m}^{3} \mathrm{~s}^{-1}\right]$ \\
Bed roughness length scale, $\mathrm{k}_{\mathrm{s}}$ & $0.1-1[\mathrm{~m}]$ \\
Hillslope angle, $\varphi$ & 10 [degrees] \\
Mean bed slope, $\mathrm{S}$ & 0.027 \\
Average rock density, $\rho_{\mathrm{s}}$ & $2700\left[\mathrm{~kg} \mathrm{~m}^{3}\right]$ \\
Water density, $\rho$ & $1000\left[\mathrm{~kg} \mathrm{~m}^{3}\right]$ \\
Kinematic viscosity at $20^{\circ} \mathrm{C}, v$ & $1 \times 10^{-6}\left[\mathrm{~m}^{2} \mathrm{~s}^{-1}\right]$ \\
Flow depth, $h$ & $170[\mathrm{~m}]$ \\
Width of the valley floor, $w$ & $700[\mathrm{~m}]$ \\
Acceleration due gravity, $g$ & $9.81\left[\mathrm{~m} \mathrm{~s}^{-2}\right]$
\end{tabular}

We used the equation of Lamb and Fonstad (2010) and solved for the bed shear stress:

$$
Q=8.1 A\left(\frac{\tau_{b}}{\rho}\right)^{\frac{1}{2}}\left(\frac{h}{k_{s}}\right)^{\frac{1}{6}}
$$

where $h$ is the flow depth and $A$ is the cross sectional area of the flow, calculated from an approximated trapezoid valley:

$$
A=h w+\tan \varphi h^{2}
$$

where $w$ is the width of the flat bottom. 
Using the $\tau_{b}$ we solve for the intermediate axis length of a median block size $\overline{D_{2}}$ using the relation:

$$
\overline{D_{2}}=\frac{\tau_{b}}{\tau^{*} C g\left(\rho_{s}-\rho\right)}
$$

where the critical stress for insipient motion, $\tau_{* C}$, was estimated from Lamb et al. (2008) and references therein:

$$
\tau_{*_{C}}=0.15 S^{0.25}
$$

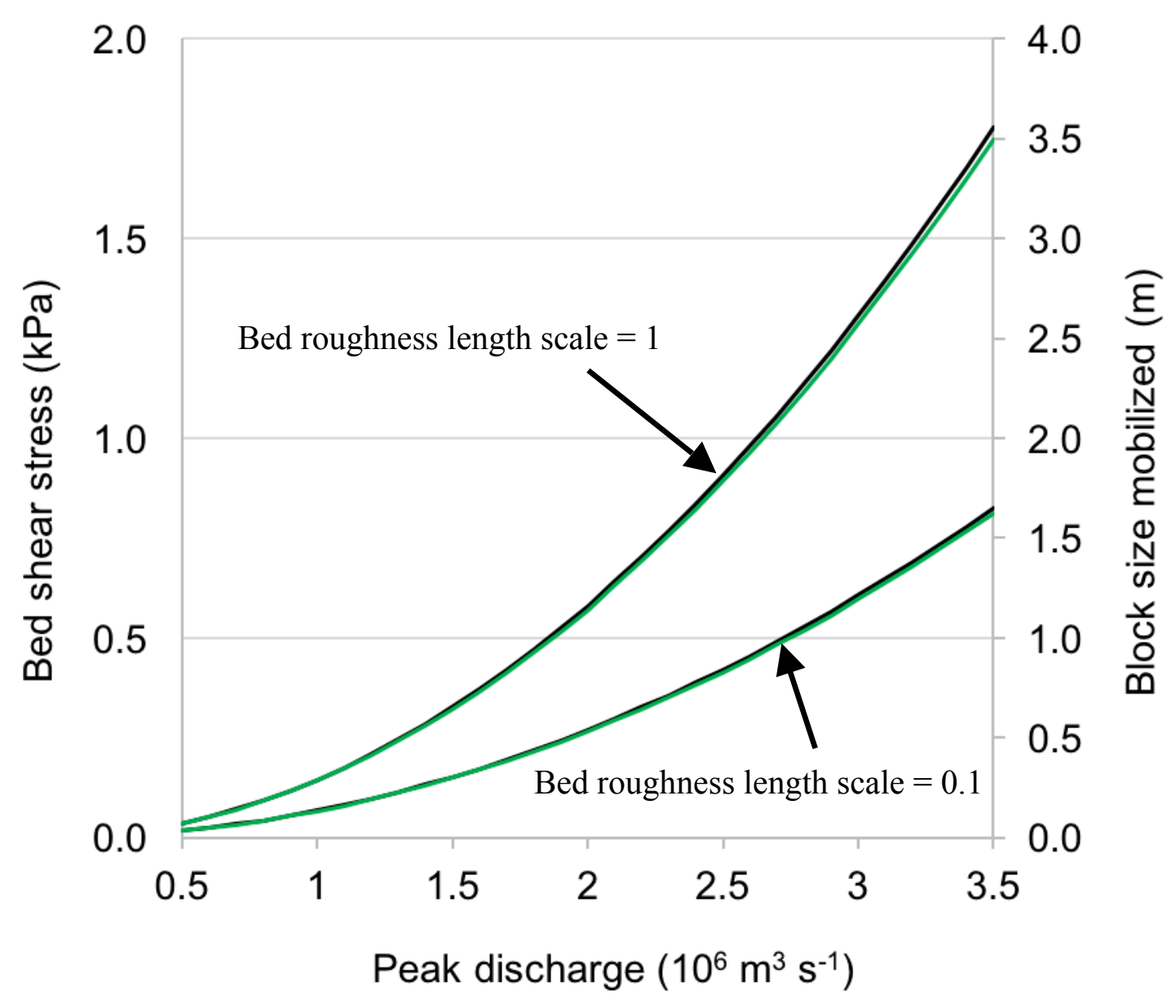

Figure S1. Calculated bed shear stress and maximum particle size mobilized in a water flow with various peak discharge through a 700-m wide gorge. The calculated values are sensitive to and directly related with the bed roughness length scale (ranging 0.1 to $1 \mathrm{~m}$ ).

The black curves are for bed shear stress, and the green curves are for block size. 
References cited in the supplementary online material

Arzhannikov, S.G., Braucher, R., Jolivet, M., Arzhannikova, A.V., Vassallo, R., Chauvet, A., Bourlès, D., and Chauvet, F., 2012, History of late Pleistocene glaciations in the central Sayan-Tuva Upland (southern Siberia): Quaternary Science Reviews, v. 49, p. 16-32.

Balco, G., Stone, J.O., Lifton, N.A., and Dunai, T.J., 2008, A complete and easily accessible means of calculating surface exposure ages or erosion rates from ${ }^{10} \mathrm{Be}$ and ${ }^{26} \mathrm{Al}$ measurements: Quaternary Geochronology, v. 3, p. 174-195.

Desilets, D., and Zreda, M., 2003, Spatial and temporal distribution of secondary cosmic-ray nucleon intensities and applications to in-situ cosmogenic dating: Earth and Planetary Science Letters, v. 206, p. 21-42.

Desilets, D., Zreda, M., and Prabu, T., 2006, Extended scaling factors for in situ cosmogenic nuclides: new measurements at low latitude: Earth and Planetary Science Letters, v. 246, p. 265-276.

Dunai, T., 2001, Influence of secular variation of the geomagnetic field on production rates of in situ produced cosmogenic nuclides: Earth and Planetary Science Letters, v. 193, p. 197-212.

Gillespie, A.R., Burke, R.M., Komatsu, G., and Bayasgalan, A., 2008, Late Pleistocene glaciers in Darhad Basin, northern Mongolia: Quaternary Research, v. 69, p. 169-187.

Heyman, J., 2014, Paleoglaciation of the Tibetan Plateau and surrounding mountains based on exposure ages and ELA depression estimates: Quaternary Science Reviews, v. 91, p. 30-41.

Komatsu, G., Arzhannikov, S. G., Gillespie, A. R., Burke, R. M., Miyamoto, H., and Baker, V. R., 2009, Quaternary paleolake formation and cataclysmic flooding along the upper Yenisei River: Geomorphology, v. 104, p. 143-164.

Lal, D., 1991, Cosmic ray labeling of erosion surfaces: in situ nuclide production rates and erosion models: Earth and Planetary Science Letters, v. 104, p. 424-439.

Lamb, M.P., and Fonstad, M.A., 2010, Rapid formation of a modern bedrock canyon by a single flood event: Nature Geoscience, v. 3, p. 477-481.

Lamb, M.P., Dietrich, W.E., and Venditti, J.G., 2008, Is the critical Shields stress for incipient sediment motion dependent on channel-bed slope?: Journal of Geophysical Research, v. 113, F02008, doi:10.1029/2007JF000831.

Lifton, N.A., Bieber, J.W., Clem, J.M., Duldig, M.L., Evenson, P., Humble, J.E., and Pyle, R., 2005, Addressing solar modulation and long-term uncertainties in scaling in situ cosmogenic nuclide production rates: Earth and Planetary Science Letters, v. 239, p. 140-161.

Rother, H., Lehmkuhl, F., Fink, D., and Nottebaum, V., 2014, Surface exposure dating reveals MIS-3 glacial maximum in the Khangai Mountains of Mongolia: Quaternary Research, v. 82, p. 297-308.

Stone, J., 2000, Air pressure and cosmogenic isotope production: Journal of Geophysical Research, v. 105, no. B10, p. 23753-23759. 